\title{
EL ENFOQUE EPISTÉMICO EN EL TRATAMIENTO DE LAS RELACIONES ENTRE ENTIDADES FEDERATIVAS*
}

\author{
THE EPISTEMIC APPROACH IN THE TREATMENT \\ OF FEDERAL STATES
}

\section{Jorge Alberto SILVA ${ }^{* *}$}

\begin{abstract}
RESUMEN: El autor cuestiona cuál es el enfoque epistémico que los tribunales judiciales y la doctrina han dado a las relaciones legales entre entidades federales. Excava desde el siglo XIX hasta el presente en leyes, doctrinas y decisiones judiciales. Sostiene que el tratamiento ha sido desconcertante en sus reformulaciones; en algunas ocasiones, el conocimiento de las relaciones interestatales se ha hecho depender del derecho constitucional, el derecho internacional privado, del derecho civil, etcétera.
\end{abstract}

Palabras clave: Derecho interestatal, estado federal, tráfico jurídico, enfoque epistémico, doctrina, precedentes judiciales.
ABSTRACT: The author questions the epistemic approach that judicial courts and doctrine have given to legal relations between federal entities. Excavates from the nineteenth century to the present in laws, doctrines and judicial decisions. He maintains that the treatment has been disconcerting in his reformulations; On some occasions, knowledge of interstate relationships has been made dependent on constitutional law, private international law, civil law, etc.

Keywords: Interstate law, federal state, legal traffic, epistemic approach, doctrine, judicial precedents.

* Artículo recibido el 2 de abril de 2018 y aceptado para su publicación el 23 de septiembre de 2019.

** ORCID: 0000-0003-0809-5916. Profesor de derecho conflictual. Presidente de la Asociación Nacional de Profesores de DIPr. Investigador nacional (Conacyt), nivel III. Correo electrónico: silvasi@aol.com.

Boletín Mexicano de Derecho Comparado, nueva serie, año LI, núm. 156, septiembre-diciembre de 2019, pp. 1637-1667.

Esta obra está bajo una Licencia Creative Commons Atribución-NoComercial-SinDerivar 4.0 Internacional, IIJ-UNAM. 
SUMARIO: I. Introducción. II. Calificación del supuesto fáctico en el jurídico.

III. El punto de partida para conocer lo prescrito en las disposiciones constitucionales. IV. Conclusión. V. Referencias bibliográficas.

\section{INTRODUCCIÓN}

México se encuentra organizado como un Estado federal, conformado por diversas entidades federativas; cada una cuenta con su propia legislación, diferentes entre sí y, en ocasiones, opuestas en su contenido. ${ }^{1}$

El panorama plurilegislativo cobra importancia al surgir problemas relacionados con la vinculación entre los ordenamientos jurídicos de cada entidad. Los operadores jurídicos, abogados y jueces, ante la diversidad legislativa, se cuestionan cómo resolver cada problema de tráfico jurídico interestatal. $^{2}$

El derecho interestatal toma como objeto de conocimiento enunciados jurídicos cuyas principales disposiciones se encuentran en la Constitución general. En ésta, destacan los artículos 106 y 121, que incluyen enunciados prescriptivos sobre competencia judicial y legislativa, enfocados en la regulación de relaciones interestatales.

Destaca la denominada cláusula de entera fe y crédito, conforme a la cual los actos, registros y procedimientos de una entidad federativa deben ser reconocidos en las demás entidades federativas. Se incluyen algunas bases sobre la que debe descansar la normatividad secundaria (federal y de cada entidad federativa). ${ }^{3}$ En torno a la competencia entre entidades, agrégase el artí-

1 Cada entidad no sólo tiene sus propios órganos de gobierno (gobernador, poderes Legislativo y Judicial), sino que también suele producir leyes y decisiones propias, no necesariamente iguales o similares a las de las demás entidades federativas, de ahí la autonomía legislativa de cada entidad, que suele diferenciarse de las leyes de otras.

2 La expresión problema de tráfico jurídico es propia del metalenguaje, y es empleada por varios juristas (v. g., Pereznieto Castro, José Luis Siqueiros, etcétera). Supone una conducta que puede constituirse o iniciarse bajo un orden jurídico, y continuar o producir efectos jurídicos bajo otro orden $(v . g$, se otorga un testamento en un lugar y se pretende que se le reconozca en otro). Se trata de una cuestión fáctica (los supuestos fácticos), que es tomada por el derecho para resolver no sólo los mal llamados problemas de conflictos de leyes, sino también los de competencia entre entidades, tanto para decidir cuál es el ordenamiento a aplicar como el estado y las autoridades que han de conocer y resolver.

3 Las Constituciones previas a la de 1917 regularon algunos problemas interestatales, pero fue la de 1917 la que introdujo algunas prescripciones conflictuales en las llamadas

Esta obra está bajo una Licencia Creative Commons

Atribución-NoComercial-SinDerivar 4.0 Internacional, IIJ-UNAM.

Boletín Mexicano de Derecho Comparado, núm. 156, pp. 1637-1667. 
culo 106 constitucional, que atiende a las relaciones horizontales entre las entidades, diferenciadas de las verticales ( $v . g$., entre el gobierno federal y las entidades). Ambos enunciados son de jerarquía suprema e imperativa.

$\mathrm{El}$ artículo 121 contiene algunas prescripciones jurídicas que uniforman los ámbitos sustantivo e interestatal de cada entidad federativa. Al respecto, prescribe:

Art. 121. En cada entidad federativa se dará entera fe y crédito de los actos públicos, registros y procedimientos judiciales de todas las otras. El Congreso de la Unión, por medio de leyes generales, prescribirá la manera de probar dichos actos, registros y procedimientos, y el efecto de ellos, sujetándose a las bases siguientes:

I. Las leyes de una entidad federativa solo tendrán efecto en su propio territorio y, por consiguiente, no podrán ser obligatorias fuera de él.

II. Los bienes muebles e inmuebles se regirán por la ley del lugar de su ubicación.

III. Las sentencias pronunciadas por los tribunales de una entidad federativa sobre derechos reales o bienes inmuebles ubicados en otra entidad federativa, solo tendrán fuerza ejecutoria en esta, cuando así lo dispongan sus propias leyes. Las sentencias sobre derechos personales solo serán ejecutadas en otra entidad federativa, cuando la persona condenada se haya sometido expresamente o por razón de domicilio, a la justicia que las pronunció, y siempre que haya sido citada personalmente para ocurrir al juicio.

IV. Los actos del estado civil ajustados a las leyes de una entidad federativa, tendrán validez en las otras.

V. Los títulos profesionales expedidos por las autoridades de una entidad federativa con sujeción a sus leyes, serán respetados en las otras.

Acorde al artículo 106, el poder o competencia judicial de cada entidad federativa podrá ser ejercida por cada entidad. Pero en las hipótesis de controversia entre ellas, en torno al ejercicio del poder (las relaciones horizontales), el orden jurídico federal será el que resuelva (artículo 124 constitucional). Al respecto, la Constitución prescribe:

Art. 106. Corresponde al Poder Judicial de la Federación, en los términos de la ley respectiva, dirimir las controversias que, por razón de competencia, se

bases del artículo 121. Algunos autores prefieren referirse a ellas como fracciones o apartados. Yo utilizaré la expresión lingüística empleada por la Constitución: bases. 
susciten entre los Tribunales de la Federación, entre éstos y los de las entidades federativas o entre los de una entidad federativa y otra.

Estas disposiciones han sido interpretadas por los tribunales judiciales. De igual forma, los doctrinarios se han preocupado por su reformulación. El artículo 106 ha sido el menos socorrido.

Lo que me interesa destacar en las siguientes líneas no es precisamente la interpretación o significado de estos enunciados constitucionales, propios de la dogmática, sino las variables tomadas en cuenta para realizar una reformulación (judicial y doctrinal).

Es necesario conocer cómo se construye el aparato conceptual mediante el cual se determina y describe el derecho, así como los razonamientos y argumentos implicados. Pero, en especial, quiero referirme en este artículo a la cuestión ¿cuál es o ha sido el enfoque epistémico seguido por nuestra doctrina y por los tribunales para reformular estos enunciados constitucionales? De forma más específica, me interesa conocer cuál es o han sido las condiciones seguidas para sostener un criterio.

\section{Galificación Del SUPUESTO FÁCTICO EN EL JURÍDiCO}

Para conocer, es necesario que los enunciados prescritos sean reformulados en forma justificada, consistente y específica, que presenten proposiciones que deriven de un razonamiento práctico, que "digan" qué dice ese conjunto de enunciados y, en su caso, cómo es que mediante éstos se resuelve alguna laguna o se producen interpretaciones para textos vagos y ambiguos.

Pero para una reformulación jurídica y confiable no basta que se nos diga qué dicen los enunciados prescritos, sino que es necesario saber si podemos confiar en lo que se nos dice. Para esto, es necesario conocer, entre otras cosas, cómo es que el reformulador observa la realidad a la que va dirigida, ¿cuáles han sido los instrumentos epistémicos de que se ha valido? Es decir no basta la audacia o la imaginación del "intérprete" para afirmar algo, sino que es necesario conocer por qué lo afirma, en qué se ha apoyado.

Resultaría temerario hacer interpretaciones sobre estas disposiciones cuando el reformulador desconoce la hermenéutica y la epistemología. Lo que me interesa es dar a conocer cómo es que el reformulador ha calificado el supuesto fáctico dentro del jurídico $\mathrm{El}$ quid consiste en conocer cómo

Esta obra está bajo una Licencia Creative Commons

Atribución-NoComercial-SinDerivar 4.0 Internacional, IIJ-UNAM.

Boletín Mexicano de Derecho Comparado, núm. 156, pp. 1637-1667. 
ha visto ese objeto de conocimiento (me refiero a los supuestos de tráfico jurídico interestatal), cuál ha sido su procedimiento para verlo, tomar en cuenta la proposición relevante. Sabemos que no necesariamente se ha recurrido a criterios subjetivos de sistematización cognoscitiva. Me detengo en uno de estos puntos.

La acción de un juez para calificar consiste en encuadrar un supuesto fáctico en el significado de un enunciado constitucional, pero, en especial, el proceso epistémico para lograr ese encuadramiento, en especial a una disciplina jurídica. En este caso, presuponiendo que sigue un proceso intelectual científico (no ideológico), el juez subsume el dato o evento en un signo lingüístico. Es el primer paso que debe darse en todo tipo de investigación.

Analicemos el siguiente ejemplo de Neil MacCormick. Una señora fue demandada civilmente en 1958 por adulterio, pues había concebido a un hijo sin haber tenido relaciones sexuales con su marido, y sin que éste hubiera tenido conocimiento. Aunque la señora admitió haber dado a luz al hijo (una niña) sin haber tenido relaciones sexuales con su marido, demostró que el hijo fue concebido debido a un procedimiento de inseminación artificial. La cuestión judicial principal (problema de calificación) consistió en resolver si la forma en que fue concebido el hijo encuadraba en el supuesto normativo adulterio. ${ }^{4}$

Lo que quiero decir es que el juez debe comenzar diferenciando el dato u objeto establecido en una ley (el supuesto jurídico), del dato u objeto que se dice ocurrido en una realidad (el supuesto fáctico). Cada uno es diferente, debe tratársele de manera diferente. Precisar si un dato fáctico encuadra en uno jurídico no es fácil ni deriva de actos de mera intuición, ni de mera lógica formal. Si el hecho realizado por la señora del ejemplo encuadra o no en el adulterio, requiere suponer una acción epistémica (científica), metateórica. Hay que recordar que el concepto adulterio no es un concepto ontológico, que exista en sí y por sí, independiente de lo que piensa el ser humano. La definición de adulterio es propia de los seres humanos, no de la esencia de las cosas. Para determinar qué es adulterio, se suele partir de las predisposiciones sociales y contextos de la cultura

4 El ejemplo corresponde al que expone Neil MacCormick a propósito del caso MacLennan vs. MacLennan resuelto en 1958. La resolución puede verse en MacLennan (1958, S. C. 105). Otros ejemplos se encuentran en Bartholomew (1958) y Dworkin (1996). 
propia del sujeto cognoscente, actividad que nos lleva al conocimiento de los usos del lenguaje.

¿Cómo puede el juez (o cualquier otro operador jurídico) estar seguro de que esa conducta encuadra o no en el adulterio?, ¿es correcta o incorrecta la afirmación que haga un juez o un doctrinario? Un dato a tomar en cuenta, es que no hay verdades obvias. Se requiere que el intérprete del dato fáctico y del dato jurídico conozca cómo acertar cuando califica; sobre todo, saber emplear un tipo de conocimiento que lo "ilumine", que le diga cómo se resuelve. El punto al que me encamino con esta metáfora consiste en saber encuadrar un problema de tráfico jurídico interestatal en una disciplina jurídica.

Para un enfoque epistémico es importante tomar en cuenta los procesos o métodos empleados para producir un conocimiento (reformular el derecho); precisar si un cierto conocimiento es epistémico, afirmar si se ha validado el conocimiento producido. Entiendo al conocimiento epistémico (en parte) como el conjunto de conocimientos que condicionan la forma o formas en que se entiende, se crea y se interpreta el derecho. No hay que olvidar que el dogmático, al formarse una imagen del derecho, emplea una serie de instrumentos hermenéuticos para presentar esa imagen, y requiere de un procedimiento para lograr la nueva imagen o un nuevo constructo. Un discurso reformulatorio del derecho se corresponde (al menos esa es la pretensión) con la imagen que el sujeto cognoscente se forma del objeto, imagen que suele ser vista por el dogmático a través de sus lentes, por medio de los instrumentos que el mismo dogmático suele construir; actividad en la que debiera participar la hermenéutica, el razonamiento y la filosofía.

Rolando Tamayo y Salmorán — seguramente uno de los juristas mexicanos que mayormente se ha preocupado por la dogmática, al construir toda una explicación metateórica - destaca la labor de quienes conforman estudios reformulatorios. Al referirse a la jurisprudencia (en su acepción ciencia del derecho), expresa: "La jurisprudencia incorpora al mundo de la racionalidad un espacio muy importante de la razón práctica. La simple construcción de la jurisprudencia es un prodigio de la razón" (Tamayo 2003).

Permítaseme ser más preciso. Si deseo conocer correctamente alguna cosa, debo acudir a la instancia correspondiente. Por ejemplo, si deseo conocer cómo se regula jurídicamente un divorcio, acudo al derecho de 
familia; si deseo conocer cómo se regula una empresa comercial, acudo al derecho comercial; si deseo conocer cómo se encuentra organizado un Estado, debo consultar el derecho constitucional; si deseo conocer cómo se regula la relación entre los Estados de la comunidad internacional, acudo al derecho internacional.

¿A dónde debo acudir cuando deseo conocer la regulación de problemas derivados de relaciones privadas entre entidades federativas? Ésta es una de las cuestiones sobre las que concentro mi atención en este artículo. ¿Acudiré al derecho civil?, ¿al derecho procesal?, ¿al laboral?, ¿al internacional? Cada una de estas disciplinas tiene sus propios lentes con los cuales observa y describe al derecho; con éstos, reformula el apartado o rama que toma como objeto de conocimiento. Los lentes de cada disciplina no son los mismos que emplean otras disciplinas.

¿Cuál es la disciplina que se encarga de estudiar, investigar y presentar las reformulaciones en torno a los problemas de tráfico jurídico interestatal? Si el reformulador se equivoca en su respuesta, es posible que hubiera equivocado el método empleado para conocer. Seguramente ha elegido incorrectamente la disciplina o el campo de conocimiento que lo redireccione, y, con ello, en los resultados a que arribe.

Si se equivocó con la elección de la disciplina, sería tanto como confundir al futbol soccer con el futbol americano; al lago Titicaca, con Xochimilco; y, epistémicamente, lo que afirme o reformule no necesariamente será correcto. ${ }^{5}$ Debe comenzar con un punto de partida. El problema para un dogmático no consiste en decir qué dice el derecho, sino en qué actitud tomar para responder a esa interrogante.

Como afirma Rodolfo Vázquez (2008), "no es posible reflexionar y construir una teoría de las normas y del ordenamiento jurídico si no es asumiendo una toma de posición metodológica por parte del científico del derecho".

5 Debo decir que una disciplina corresponde a un constructo que sistematiza diversas teorías, explicaciones, clasificaciones, en general, la base de un paradigma de un jurista de la tradición romano-germánica. En mi caso, que procura proporcionar una serie de estándares comunes (aunque contingentes, por supuesto), que explican los vínculos jurídicos fundamentales entre los ordenamientos de las entidades. Se trata de elementos a ser tomados en cuenta en el desarrollo de un discurso disciplinar interestatal; son un punto de partida para fijar los niveles de vinculación. No obstante, el hecho de que se conforme una disciplina jurídica, eso no quiere decir que sea infalible, aislada y que carezca de vínculos inter y transdiciplinarios (Cáceres 2015). 
Pues, aunque no lo crea el lector, el hecho es que varias decisiones judiciales no han atinado en darle respuesta a la interrogante, pues han sido vacilantes en torno al punto de partida. ¿A cuál disciplina se debe acudir cuando se desea conocer la regulación de problemas derivados de relaciones privadas entre entidades federativas?

Permítaseme abordar en las siguientes líneas la problemática que interesa.

\section{EL PUNTO DE PARTIDA PARA GONOCER LO PRESGRITO EN LAS DISPOSICIONES GONSTITUCIONALES}

Reformular lo que prescriben los citados artículos 106 y 121 no es tarea fácil. Una prueba de ello han sido los múltiples y contradictorios significados judiciales y doctrinarios que se le han atribuido. ¿Cómo es que se ha conocido y reformulado lo prescrito en estos textos constitucionales?, ¿cuál ha sido el punto de partida? Los errores habidos deben imputarse a una falta de precisión. ${ }^{6}$

Adelanto que este punto de partida no está por encima del derecho positivo, sino más bien se infiere del mismo. Sus elementos tampoco son intemporales ni valen para todo lugar. Son elementos comunes inferidos de la base empírica y de diversas metarreglas que, como herramientas, sirven para identificar, interpretar, ordenar y establecer ciertos principios fundamentales. Suponen una cierta regulación de los elementos particulares observados para obtener, luego, su generalización.

6 Reformular no significa ir más allá del derecho autorizado por el sistema, como suele ocurrir en los enfoques teológicos, metafísicos, etcétera; más bien, el reformulador es quien define el punto de partida. Si el discurso prescriptivo es aquel del que se va a hablar, entonces el que habla del mismo conforma otro discurso: un discurso que no es prescriptivo. Al hablar del discurso prescrito, el reformulador lo interpreta, lo reordena, lo reconstruye, etcétera; ¡vamos!, como dijeran Alchourrón y Bulygin: reformula el sistema; es decir, sustituye la base del sistema por otra nueva, "más reducida y general, pero normativamente equivalente a la base primitiva" (Alchourrón y Bulygin 2002,128), "encontrar una base axiomática nueva, pero equivalente a la anterior; es decir, sin cambiar el sistema mismo" (Bulygin, 1991, 472) Esto es, al tomar el objeto de conocimiento forma una "imagen" de ese objeto, imagen que al ser presentada es una imagen reformulada del objeto presentado.

Esta obra está bajo una Licencia Creative Commons

Atribución-NoComercial-SinDerivar 4.0 Internacional, IIJ-UNAM.

Boletín Mexicano de Derecho Comparado, núm. 156, pp. 1637-1667. 


\section{El punto de partida}

¿Qué es lo que nuestros dogmáticos y jueces han hecho para reformular las disposiciones constitucionales sobre derecho interestatal? No basta conocer o recitar el texto jurídico prescrito, porque tampoco es aceptable que repitan los signos del lenguaje objeto, que consulten un diccionario, ni aceptar lo que otros han afirmado en torno a su sentido. A un investigador le importa comenzar conociendo la perspectiva asumida por jueces y doctrinarios al presentar sus reformulaciones, contar, a la vez, con una propia. En mi interés, para este estudio, me pregunto: ¿cuál ha sido el método seguido para acertar en el conocimiento?

Por lo general, jueces, abogados y escritores se conforman con interpretaciones sugeridas por precedentes y doctrina, lo que significa caer en el dogma. Podemos aceptarlas o rechazarlas, pero para un investigador es indispensable conocer el procedimiento seguido por el intérprete consultado. Es reprobable que un trabajo de "investigación" sólo se quede con lo que dice un autor o un precedente judicial. No cabe conformarse con un argumentum ad quietem (al reposo) o alguno ab autoritate.

Para un reformulador (juez o doctrinario) es necesario contar con un punto de partida que le facilite adentrarse en el conocimiento del texto objeto, comenzando por precisar ese punto, especialmente el tomado por la doctrina y las decisiones judiciales producidas. ¿Cuáles son los lentes con los que cuenta? Preguntémonos cuál es el área o apartado del conocimiento que nos auxilia a esto, a partir de la respuesta, se podrá conocer qué y para qué sirven esas disposiciones, cuál es su función, cómo ha evolucionado su interpretación. ${ }^{7}$

Para emprender una tarea reformulatoria, es imprescindible partir de un marco de referencia, un modelo hermenéutico, propio para la interpretación objeto de nuestro interés. Ante la diversidad de contradicciones interpretativas producidas (judiciales y doctrinarias), es necesario que nos expliquemos en forma razonada y justificada por qué los intérpretes han afirmado una específica interpretación. ¡Vamos! Se trata de conocer su punto de partida.

Cabe iniciar con la fuente jurídica de mayor importancia para la resolución de los problemas de tráfico jurídico interestatal (la Constitución),

7 Este problema lo presento en Silva (2014), donde expongo la taxonomía de las disciplinas jurídicas y las tendencias metodológicas que se han producido. 
así como para conformar la disciplina del derecho interestatal. Para lograr esto, es necesario un enfoque epistémico y metodológico. Es necesario una toma de posición en torno al punto de partida. ¿Cuál ha sido la de los reformuladores habidos?

No se trata de cualquier punto de vista, cualquier guía o dirección consultada o que se nos ocurra. Desgraciadamente no se ha sido definido este punto de partida en la doctrina de los dogmáticos ni en las resoluciones judiciales producidas. Intentaré explicar lo que de estas construcciones he percibido.

Para explicar la construcción producida hasta ahora, he procurado inferir el punto de partida de jueces y doctrinarios para conocer su punto de partida. El hecho es que ni la doctrina ni los precedentes judiciales (la racionalidad judicial) han definido su perspectiva inicial; por ello, he tratado de descubrirla, "leyendo entre líneas" la ideología subyacente. En mi búsqueda he inferido diversos "enfoques" y vestigios observados, que procuraré ir explicando.

Debemos tomar en cuenta que para una reformulación es necesario contar con unas gafas que nos permitan contemplar nuestro objeto de conocimiento. Por desgracia, no todos los que han hablado de ese objeto han contado con unas gafas, y cuando las han tenido, tampoco han sido las correctas.

Explicaré lo que he observado en mi indagación: entre la Constitución de 1824 y la de 1857 no encontré doctrina ni decisiones judiciales de interés que me permitieran conocer algún enfoque epistémico adecuado. No obstante, no debo olvidar algunos textos y opiniones que observaron a las entidades federativas como soberanas, y, prácticamente, conformando una confederación, no exactamente un estado federal. No fue hasta después de la segunda mitad del siglo XIX cuando comenzaron a darse a conocer algunos elementos que me proporcionaron algunos datos para inferir la perspectiva epistémica asumida.

Desde entonces, y casi hasta ahora, he podido advertir que las reformulaciones habidas han partido de diversas direcciones metodológicas. Han sido tomadas como parte del derecho civil, del derecho procesal, del derecho constitucional, del derecho internacional privado. Los juicios han sido oscilantes. Ninguno ha observado las disposiciones constitucionales interestatales (el objeto de conocimiento) como parte de una disciplina 
autónoma, con un propio enfoque epistémico; esto es, con una específica matriz disciplinaria.

Por lo general, la aprehensión del objeto de conocimiento ha sido un tanto intuicionista a la manera "inmediata", no la "mediata", que nos permite emplear inferencias y razonamientos.

A mi parecer (debo adelantarlo), el enfoque que debiera adoptarse debe ser uno propio o autónomo, específico para una propia disciplina: la del derecho interestatal. Los tribunales judiciales han contribuido a moldear una perspectiva metodológica, aunque con oscilaciones contradictorias, bastante paradójicas y, a mi parecer, alejadas de un aceptable enfoque epistémico.

Presento enseguida las perspectivas legislativas, judiciales y doctrinarias que he inferido a partir de los tratos e interpretaciones producidos al paso del tiempo.

\section{Perspectiva legislada}

Inicio con la Constitución de 1824 (la que conformó a México como Estado federal). Por ese entonces, se asentó, como posibilidad, "uniformar las leyes" del país. Su artículo 143 expresaba, en seguida de la cláusula de entera fe y crédito: "el Congreso General uniformará las leyes, según las que deberán probarse dichos actos, registros y procedimientos". Aunque esto fue lo establecido por los legisladores (constituyentes) del texto constitucional, no me parece que realmente se hubiera procurado "uniformar las leyes del país" ni que sirviera para construir un argumento psicológico; más bien se trataba de conformar un estado federal. Tan es así, que en la Constitución de 1857 aquella redacción fue eliminada. Más bien, los legisladores procuraron un estado federal para unir lo que se estaba desuniendo.

Lo que yo infiero es que en esa Constitución de 1824 se procuró asegurar la vinculación entre los estados (incluidos líderes en pugna), que luego conformaron la Unión, en términos bastante semejantes al enfoque diseñado para la conformación del texto constitucional estadounidense, texto que, aunque con una incorrecta traducción, se procuró reproducir en parte. Ese diseño inicial tampoco se encaminó para introducir normas conflictuales, como algunos suelen creer y afirmar. 
Debo resaltar que, aunque la cláusula de entera fe y crédito fue importada de Estados Unidos, ${ }^{8}$ el sentido y significado que al paso del tiempo se le ha dado en México ha sido diferente a la del lugar de su origen. No hay que olvidar que aunque los constituyentes de 1824 tuvieron a la mano un ejemplar de la Constitución estadounidense, México prácticamente se desmembraba. Por un lado, Chiapas, Guatemala, Jalisco, Oaxaca, Zacatecas, entre otros, deseaban su independencia. La construcción de un orden federal en México sirvió para unir lo que se estaba desuniendo.

Se crearon las entidades federativas con un "gobierno propio" y darse sus propias leyes, pero desgraciadamente no se tomaron muy en serio las relaciones entre ellas. De hecho, así ha sido hasta ahora.

\section{Perspectiva judicial}

Al paso del tiempo, y al surgir los problemas de tráfico jurídico interestatal, que han sido objeto de conocimiento de los tribunales, éstos imaginaron esas relaciones interestatales desde una perspectiva internacionalista, presuponiendo una soberanía plena para cada entidad federativa, según se infiere de sus criterios. Estimaron que cada entidad era soberana, casi de la manera misma como lo es un Estado de la comunidad internacional. ${ }^{9}$ Los enfoques producidos han sido variables; unos, se refieren al derecho aplicable; otros, a la competencia de la entidad.

\section{A. Primeras decisiones}

Las cuestiones relacionadas con la determinación de cuál era la entidad federativa que había de conocer y resolver un problema de tráfico jurídico interestatal se produjeron desde antes de la época de las codificaciones de cada entidad. Las decisiones relacionadas con el orden jurídico sustantivo que regulaba el fondo del asunto vinieron después con la tarea

8 Texto de Estados Unidos: "Full faith and credit shall be given in each State to the public acts, records, and judicial proceedings of every other state. And the Congress may by general laws prescribe the manner in which such acts, records and proceedings shall be proved, and the effect thereof".

9 Todavía en 1938 así pareció entenderse por la SCJN (SJF AD 6020/37,registro: 816857).

Esta obra está bajo una Licencia Creative Commons

Atribución-NoComercial-SinDerivar 4.0 Internacional, IIJ-UNAM.

Boletín Mexicano de Derecho Comparado, núm. 156, pp. 1637-1667. 
codificadora de finales del siglo XIX, lo que obligó a que las lagunas técnicas tuvieran que ser colmadas por parte del Poder Judicial. Esto es, primero surgieron los asuntos competenciales (cuál es la entidad federativa competente), después, los que eligieron el orden jurídico sustantivo (cuál es el orden jurídico regulador). En seguida presento algunos ejemplos de esa naciente época para el derecho interestatal:

a) Una resolución que me llama la atención (último tercio del siglo XIX), debido al manejo de los argumentos (pobres y equivocados) fue la que se presentó entre un juez del D. F. (la hoy CDMX) y un juez de Huamantla, Tlaxcala. El punto central giró en torno al llamado "fuero del labrador", fuero que le atribuía poder o competencia al foro del lugar de la labranza. El asunto fue que unos labradores demandados tenían su domicilio y lugar de labranza en Huamantla; pero, a pesar de ello, fueron demandados en el D. F. El juez de Huamantla planteó la incompetencia del juez del D. F., y, éste, siguiendo la opinión sugerida por el actor, negó que el de Huamantla fuera competente.

En esta resolución, el actor presentó la siguiente cadena de razones y premisas: el fuero del labrador se consigna en la Novísima Recopilación; pero esta disposición es inconstitucional, ya que la Constitución de 1857 prohíbe los fueros especiales. Esta explicación la presentó el juez del D. F. al juez de Huamantla pidiéndole que antes de continuar con el procedimiento se "desistiera de la incompetencia" que "inconstitucionalmente" había planteado. El juez de Huamantla accedió a lo que se le pidió a partir de una inferencia o representación inválida, equivocada y falsable. En realidad, una falacia derivada de una ambigüedad (falacia del equívoco). El comportamiento final se desvió hacia una línea diferente a la que motivó el imput.

Como se infiere, es obvio que contraepistémicamente se confundió el fuero del labrador (la competencia del tribunal del domicilio) con el fuero a que alude la Constitución (la existencia de tribunales especiales) (El Foro 1873, 250). La resolución muestra la ignorancia y manipuleo de los sentidos semánticos y de las normas de adjudicación o competenciales a partir de significados ambiguos por parte del juez del D. F., haciendo evidente la confusión de los contextos jurídico-conceptuales. ${ }^{10}$

10 Poco tiempo antes de este asunto, la SCJN (en la época del Imperio de Maximiliano, noviembre 3 de 1864) había resuelto un caso suscitado entre los jueces de Puebla y 
b) Los Anales del Foro Mexicano reportan haberse resuelto, en 1864, una cuestión competencial entre los jueces del estado de Guerrero y el estado de México respecto al conocimiento y resolución de un juicio sucesorio. En éste, se cuestionó si el juez competente era la autoridad del lugar donde estaba el domicilio del de cujus (donde ejercía como cura de Apaztla) o el del lugar donde se encontraban la mayoría de sus bienes. La SGJN resolvió a favor del primer foro. En la resolución no se partió de doctrina alguna de derecho procesal o de derecho internacional, sino que sólo se citaron diversas leyes que provenían de 1812 a 1837. No hubo un punto de partida (Anales del Foro Mexicano 1864, tomo I, 73).

c) Hay una resolución que presenta un argumento, influido por un enfoque epistémico, que resalta una noción específica de la soberanía de cada entidad federativa; esta concepción de una soberanía decimonónica le cerró las puertas a la cooperación interestatal, ni siquiera observada en el ámbito internacional. En el estado de Puebla se seguía un proceso que derivó en el embargo de unos bienes que estaban en Zongolica, Veracruz. La persona beneficiada con la sentencia pidió que se enviara un exhorto a Veracruz a fin de convocar postores para el remate del bien. El supremo tribunal poblano se negó a enviar el exhorto, con el argumento de que la autoridad veracruzana no podía realizar un acto vinculado a Puebla.

El asunto llegó a la SCJN. Ésta resolvió que no es contrario a la Constitución que la autoridad de un estado presida el remate de los bienes ubicados en otro (caso del señor Luis Olivier, núm. 972). Como se observa, los argumentos poblanos muestran la concepción que de la "soberanía" sostenían, lo que se traducía en impedir las relaciones interordinamentales, y que no era diferente de la noción que se sostenía en otras entidades. Ni la representación mental o lingüística que del significado de soberanía de una entidad (su autonomía) se sostenía, fue diferenciada de lo que usualmente significa soberanía (la super omnia).

Además de esta noción de la soberanía, la resolución encubrió una forma de imponer la lex loci factum, dogma de la época con la que se confunde el lugar donde rige un específico orden, con el lugar donde ejercen

Tlaxcala, donde tomó en cuenta el fuero del labrador, definiéndolo como el privilegio de un labrador para no ser demandado fuera del lugar de la labranza (Anales del Foro Mexicano 1865, tomo II).

Esta obra está bajo una Licencia Creative Commons

Atribución-NoComercial-SinDerivar 4.0 Internacional, IIJ-UNAM.

Boletín Mexicano de Derecho Comparado, núm. 156, pp. 1637-1667. 
su función las autoridades de un estado. ${ }^{11}$ No es difícil afirmar que el punto de partida en esta resolución poblana consistió en ver a su Estado en forma similar a como se observa a un estado de la comunidad internacional. ${ }^{12}$

d) Al finalizar el siglo XIX, e inicios del XX, se resolvieron otros problemas interordinamentales. El Foro y el Semanario fudicial de la Federación registran algunos casos relacionados con profesionistas a los que no se les quiso reconocer el título que les habían otorgado las autoridades de una entidad. En estas resoluciones, la SGJN argumentó que acorde a la cláusula constitucional de entera fe y crédito, debía reconocerse el título a cada uno de los beneficiados, con el fin de que ejercieran su profesión. En ese entonces aún no estaba vigente la actual base $\mathrm{V}$ del artículo 121 constitucional. Llama la atención el argumento expuesto en una de estas resoluciones, pues no sólo se recurrió a la cláusula de entera fe y crédito, sino al derecho a la libertad de trabajo (que fue el argumento central): como la norma común prescribe la libertad de trabajo, de ésta se sigue que no se puede desconocer un título profesional (SCJN 2005). ${ }^{13}$ Es evidente la confusión de los contextos jurídico-conceptuales; en especial el epistémico. Su punto de partida fue el derecho del trabajo.

e) Una sentencia posterior resolvió un problema un tanto similar, que implicaba una definición específica de la "soberanía" de cada entidad federativa, al cuestionarse la posibilidad de que una autoridad exhortara a la de otra entidad federativa (SCJN 2005). ${ }^{14}$

Aunque se resolvieron varios casos similares, en ninguno se apeló a los lineamientos de alguna matriz disciplinar específica ni se generaron criterios o proposiciones doctrinarios de importancia, ni se aludió a problemas de tráfico jurídico interestatal. El enfoque metodológico para re-

11 A reserva de lo que poco más adelante explicaré, cabe adelantar que del hecho de que un supuesto fáctico se realice fuera del territorio de un estado no significa que sus autoridades tengan prohibido conocerlo y resolverlo. El territorio, como elemento del Estado, delimita la actividad de sus autoridades. Sólo dentro de ese espacio pueden realizar sus actos de poder. $743,848)$.

13 Los casos corresponden a Manuel Zamora (1883), José Padró (1902) y Fernando Cano (1893).

14 Caso del señor Francisco Ortiz Borbolla (1901, caso 1523). 
solver partió de un punto metodológico no definido, tal vez más intuitivo o consecuencialista.

A pesar de la ausencia de un punto de partida específico, estas primeras resoluciones muestran una concepción o modelo mental ${ }^{15}$ especial de la soberanía estatal, con carácter egocentrista, con un significado similar al de un Estado de la comunidad internacional, presentadas como comunidades jurídicas independientes, conjuntos aislados, como si fueran islotes, sin posibilidad de vincularse. ${ }^{16}$ En ninguna resolución se diferenció el lugar en el que una autoridad podía ejercer su poder, del lugar donde se suscitaban los hechos objeto de la controversia judicial (lex loci delictus).

Las entidades federativas se comportaron como si fueran totalmente soberanas y mezquinas, por lo que no solían admitir las decisiones de otras. Nos retrata una actitud independentista, egoísta y cerrada, carente de políticas cooperativas, contraria a la cláusula constitucional de entera fe y crédito. Nos presenta una percepción exagerada de cómo se apreciaban los ordenamientos paralelos (subordenamientos) a partir de un concepto del poder irreconciliable con la cooperación recíproca, una forma de razonar impeditiva de la relación interordinamental, apoyada en un enfoque egoísta de "defensa de la soberanía" (un desencaje total entre las entidades que componen "el estado de la Unión").

\section{B. Decisiones con enfoque internacional-privatistas}

En otro momento, el punto de partida fue el derecho internacional privado, como matriz disciplinaria. A los intérpretes les pareció que la directriz de esta disciplina era la misma para el derecho interestatal. Fue como confundir el género musical rock and roll con el vals.

Citaré, como muestra, algunas de las resoluciones de los más altos tribunales durante el siglo XX, que siguieron el modelo (me refiero al modelo a forma o esquema de imitar o reproducir un constructo) "el derecho interestatal es parte del Derecho internacional privado".

15 Enrique Cáceres $(2015,2220)$ explica que "Los modelos mentales son las cartas de navegación que determinan la manera en que interactuamos con el mundo y los demás".

16 Iglesias (1874). En este estudio, el autor presenta su percepción, en la que dice que cada entidad federativa parece comportarse como soberana y única en una confederación. Una reformulación similar se aprecia en Montiel y Duarte (1874).

Esta obra está bajo una Licencia Creative Commons

Atribución-NoComercial-SinDerivar 4.0 Internacional, IIJ-UNAM.

Boletín Mexicano de Derecho Comparado, núm. 156, pp. 1637-1667. 
a) En 1929, en un asunto hipotecario, la SCJN vaciló entre la lex loci rei sitae y la lex loci formam, y, aunque también aludió a los estatutos, se apoyó (así lo dijo) en los "principios que rigen en Derecho internacional privado" para decidir por la primera, pero sin explicar cómo infirió estos principios, sus premisas y su contenido, ni por qué los principios del derecho internacional privado (en adelante DIPr) eran transmutables al derecho interestatal (SJF 1921, AD 209/29, registro: 287450). Nada dijo sobre las metarreglas a que recurrió ni cómo es que la teoría estatutaria se relacionaba con el caso.

b) En 1931, la SCJN, en un asunto derivado de un divorcio en el que se confrontó el ordenamiento jurídico del D. F. con el del estado de Morelos, afirmó que "en caso de conflicto, de las dos legislaciones, la cuestión debe decidirse ocurriendo a las doctrinas de Derecho internacional privado" ${ }^{17}$ No proporcionó las razones para demostrar lo que afirmó ni por qué acogió constructos de la disciplina iusinternacional privatista, como si fueran una fuente del derecho.

c) En el mismo año, y en el caso de la notificación de una demanda de divorcio, en un problema de tráfico jurídico interestatal, cuyas leyes sobre la notificación eran diferentes, dijo: “...en caso de conflicto de las dos legislaciones, la cuestión debe decidirse ocurriendo a las doctrinas de derecho internacional privado ( $S F F$ 1931, AR 608/31, registro: 363377)".

\section{d) Dos años después (1932), la SGJN asentó en una sentencia:}

...varios autores de Derecho internacional privado, al tratar de la esfera de aplicación de las leyes, se refieren, en primer lugar, a lo que se llama "ámbito de la ley", que comprende el conflicto internacional, por la coexistencia de diversas soberanías, y el conflicto interregional, por la existencia de diversas legislaciones, como es el caso en nuestro país. Ambos conflictos se rigen, a falta de leyes expresas, por los principios de ese derecho (SFF 1933, AD 3737/31, registro: 362337$)$.

Esto es, los principios inferidos para el DIPr son los mismos que para el derecho interestatal. Nada se dijo respecto a la diferencia entre el DIPr

17 SfF 1931, AR 608/31, registro: 363376. En esta resolución se invocó "el principio locus regit actum" (así le llamó), con el que la SGJN resolvió un problema de tráfico jurídico entre entidades federativas, apelando a la analogía. ¿Cómo lo infirió? No lo dice. 
y el derecho interestatal. Simplemente, se presumió que ambas siguen la misma matriz disciplinaria (Khun 1971 ). ${ }^{18}$

e) Un año más tarde (1933), la SCJN, afirmando seguir la medieval teoría estatutaria, sostuvo con relación a unos inmuebles, que éstos se "rigen de acuerdo con los principios del derecho internacional privado, por las leyes que norman el contrato de matrimonio" (SFF 1933, AR 4489/31, registro 362367). En esta resolución, su enfoque epistémico partió del DIPr, a pesar de que se trató de un problema de tráfico jurídico entre entidades federativas. El puente que empleó fue la teoría de los estatutos, pero lo llamativo es que no dijo cómo y por qué es que esta teoría fue llevada al ámbito interestatal ni por qué se apeló a la teoría estatutaria, que el código de 1928 ya había rechazado para lo internacional.

f) En 1938, la SCJN resolvió otro asunto interestatal, donde afirmó haberse apoyado en los principios del derecho internacional privado (los de esta disciplina). Se trató de decidir cuál era el ordenamiento que regía la adquisición de unos bienes inmuebles. En su ratio decidendi, el tribunal asentó que según los principios y disposiciones del DIPr el estado y capacidad se rigen por el estatuto personal (otra vez la teoría estatutaria). Curiosamente, en esta sentencia, la SCJN se negó a aplicar la segunda base del artículo 121 constitucional, que establece la regla lex loci rei sitae, ${ }^{19}$ al darle preeminencia a ciertas proposiciones doctrinarias del DIPr. Nada dijo sobre el porqué se recurrió a un "estatuto personal".

g) En 1942, la SCJN dictó una sentencia que se apoyó en el texto doctrinario de DIPr de Juan Paulino Niboyet, un jurista francés, que aludía a la doctrina de otros juristas. Se trató de los iusinternacionalprivatistas Bouhier, Froland, Boullenois, Bourjon, Bacquet y Savigny, que aparecen citados en la obra de Niboyet (1974), lugar de donde la SGJN copió la cita, sin consultar las obras mencionadas, según se observa de la lectura completa de la sentencia. ${ }^{20}$

18 Una ciencia (o un área del conocimiento) parte de diversos elementos ordenados que conforman una matriz disciplinaria en el sentido kuhniano.

$19 S f F$ 1938, AR 4747/38, registro: 356215. Nótese que no alude a normas de DIPr, sino a principios.

20 SfF 1942, AR 7163/41, registro: 326574. Por esta época, la obra de Niboyet era empleada como libro de texto en las universidades. El caso resuelto es llamativo, pues no existía fundamento legal alguno para acoger la vinculación domiciliar, en esa época, salvo el criterio particular de un jurista francés, que fue tomado como palabra de la ley para resolver un problema interestatal, imponiéndose, irregularmente, la ley domiciliar. 
La SCJN tampoco explicó por qué se recurrió a las sistematizaciones o constructos propios de la disciplina iusinternacionalprivatista, y precisamente extranjera, ni el porqué de la relación de ésta con el orden jurídico mexicano. ¿Cómo fue que la doctrina internacional de otro país fue acogida como fuente del derecho interestatal mexicano?, ¿cuál fue la metarregla para tomarla en cuenta y realizar esta transferencia? No lo dijo. En la resolución tampoco se percibe un deslinde entre el lenguaje objeto y el metalenguaje. De lo que se trataba era de resolver, y se resolvió: pero faltó la secuencia de razones que explicaran por qué se tomó una opinión extranjera y de otra disciplina, como si fuera una fuente del derecho mexicano para marcar el punto de partida o enfoque epistémico asumido.

h) En 1954, la SCJN acudió a ciertas proposiciones doctrinarias del DIPr, al afirmar que las leyes que rigen el estado y capacidad de las personas siguen a éstas y les son "inherentes a otras relaciones o situaciones jurídicas". Lo anterior, a pesar de la territorialidad recalcitrante del CCDF de la época. En su sentencia, al resolver un asunto interestatal, afirmó que la forma de los actos jurídicos se rige por la ley del lugar de la ubicación de los inmuebles (SFF 1958, 1528, AD 708/52, registro 3411292). Aunque se recurrió a lo que se dijo era una proposición del DIPr, se trata de una proposición incorrecta, pues difícilmente esta proposición es acogida por los dogmáticos del DIPr o los enunciados legales. Esto es, partió de una premisa no adecuada a la disciplina que corresponda al derecho interestatal.

i) En 2015, la SCJN volvió a tomar en cuenta los lineamientos del DIPr. Se trató de un asunto meramente privado, en el que se demandó la nulidad de un contrato. Asentó que las "reglas" del artículo 121 "cumplen una función equivalente a las relativas al Derecho Internacional Privado en lo relacionado con el llamado conflicto de leyes, derivado de las diferencias entre las legislaciones, con el fin de determinar la ley aplicable para hacer respetar los derechos y obligaciones que nacen de éstas". ${ }^{21}$

Ahora, se empleó la expresión equivalente al DIPr, obviándose un delineado enfoque epistémico. El problema fue que no se explicó en qué consiste la equivalencia.

Nótese que en las primeras decisiones que resumo se resolvió que el punto de partida debe ser acorde a los "principios jurídicos del DIPr",

21 SfF 2015, AR 3883/2014, registro 2014692. La transcripción no corresponde al extracto, sino a parte de la sentencia. Puede consultarse en: http://wrww2.scjn.gob.mx/ConsultaTematica/PaginasPub/DetallePub.aspx?AsuntoID=169730, p. 39, párrafo 118. 
pero en ninguna de estas sentencias se explicó en qué consisten esos principios, cuál es su contenido, ni cómo se infieren (las premisas de las cuales surgen), si son preexistentes al derecho o su relación con el caso resuelto. Tampoco explicó por qué se partió de la matriz disciplinaria del DIPr y no a lineamientos del derecho regulatorio de un Estado federal; tampoco se dijo cuál es la conexión "lógica" entre un principio de DIPr y uno de derecho interestatal.

A mi entender, el recurso a principios (por esa época) suponía que éstos eran suprapositivos, que se carecía de disposiciones positivadas y que había un derecho preexistente o por encima del prescrito (un enfoque ontológico), algo propio de la metafísica. No se explicó de dónde se infirieron, por qué son "fundamentales", ni por qué precisamente "principios". Se careció de racionalización para obtenerlos. A mi parecer, fue un medio para encubrir la ignorancia de una matriz disciplinaria específica.

\section{Decisiones con enfoque procesalista}

Los tribunales también produjeron decisiones que tuvieron como marco la directriz disciplinaria del derecho procesal. En estas decisiones, relacionadas con enfoques procesales entre entidades, tampoco se presentaron explicaciones especiales o aclaraciones.

Bajo esta perspectiva, varias resoluciones judiciales se apoyaron en teorías y conceptos tomados del derecho procesal para reformular la regulación procesal intraestatal, especialmente la relacionada con la competencia de cada entidad (aquí debe tomarse en cuenta que cada entidad federativa cuenta con su propio código procesal civil y familiar), pero sin fundamentar su decisión en alguna disposición interestatal.

De esta manera, las construcciones doctrinarias de la disciplina procesal fueron llevadas a resolver problemas interestatales. En estas decisiones se confundió la norma que elige a un juez (dentro de una entidad) con la que selecciona a una entidad (la competencia estatal con la competencia de cada órgano de gobierno). Aun hasta ahora, los tribunales no han atinado a definir esta diferencia. Han seguido el modelo "el derecho interestatal es parte del Derecho procesal".

Diversas reformulaciones doctrinarias del derecho procesal (cuando eran conformadas para una sola entidad u orden jurídico) fueron llevadas al plano interestatal (donde había dos o más ordenamientos y autoridades

Esta obra está bajo una Licencia Creative Commons

Atribución-NoComercial-SinDerivar 4.0 Internacional, IIJ-UNAM.

Boletín Mexicano de Derecho Comparado, núm. 156, pp. 1637-1667. 
autónomas). Así ocurrió en las resoluciones de acumulación, de procedimientos de inhibitoria y de declinatoria. Por lo general, en estas decisiones, las cuestiones interestatales fueron tratadas como un capítulo del derecho procesal (el intraestatal), y no con autonomía; esto es, considerando una perspectiva específica para las relaciones interestatales interordinamentales. Aquí se han extrapolado argumentos procesales para resolver cuestiones interestatales.

a) En las primeras resoluciones habidas, llamó la atención una de 1878. Se trató de un juicio hipotecario iniciado en la CDMX, pero un juez de Guanajuato, ante el que se planteó un concurso de acreedores, pidió la acumulación del asunto que se seguía en la CDMX. La SCJN resolvió favorablemente que se acumularan en Guanajuato. El hecho es que en torno a esta resolución, un editorial de El Foro, escrito por José Ma. Villela (1878), cuestionó el actuar del alto tribunal. Argumentó que no existía disposición alguna para este proceder de la SCJN, y que el DIPr, sobre el que se había fundado, no era derecho vigente en México.

Aquí hay que tomar en cuenta que durante el virreinato los asuntos eran trasladables de una ciudad otra; pero los tribunales, ya en un estado federal, no atinaron a ver que ya no se estaba en un estado central.

b) Recurriendo a una transferencia conceptual semejante, la SCJN (en la segunda mitad del siglo XX), para resolver un problema de litisconsorcio, en el que las causas se encontraban en diferentes entidades federativas, se apoyó tanto en el Diccionario de derecho procesal civil de Pallares como en el derecho procesal civil, de Jaime Guasp, y en las Instituciones del proceso, de Carnelutti; y en los Ensayos de derecho procesal civil, de Chiovenda (SFF 1980, Competencia 57/79, registro 240822), ninguno de los cuales corresponde a una obra enfocada en reformular relaciones interordinamentales, sino procesales, que partieron de un único orden jurídico y de una matriz disciplinaria intraestatal.

Quienes resolvieron estos problemas no parece que se hubieran percatado de que antes que estar resolviendo un problema meramente procesal, de índole intraestatal, había un problema interordinamental (entre ordenamientos autónomos), que debía resolverse previamente. Confundieron las normas que le atribuyen competencia a una entidad (las que le otorgan poder a un ente descentralizado) con las de competencia de los órganos de ese ente (capacidades de los órganos de una entidad para conocer y resolver dentro del territorio que se les asigna). 
Esta manera de "ignorar" la relación interestatal e inicio con soluciones meramente procesales no ha sido expresada mediante argumentos racionales, ni siquiera en la doctrina de los juristas. Ninguna resolución aclara por qué evita abordar la problemática interordinamental (como premisa previa), necesaria para una toma de posición epistémica. Por desgracia, este tipo de razonamientos, que dejan de considerar una premisa o antecedente, se suelen advertir con frecuencia por parte de nuestros tribunales y nuestra doctrina. De esta forma, se han llevado teorías y conceptos de la disciplina procesal a la resolución de problemas interestatales, ignorando el marco interestatal.

En la cuestión de competencia, los juzgadores han incumplido las reglas de la implicación lógica, pues sin decirlo han implicado las normas de competencia de una entidad en las normas de competencia de los órganos de una entidad. Han presupuesto, equivocadamente, que todas las entidades se rigen bajo un mismo orden jurídico, e ignoran la autonomía de cada entidad y la necesidad de tomar en cuenta una relación interordinamental.

El hecho observado es que no se suele tomar en cuenta el primer paso y se comienza con el segundo. La competencia interestatal (un paso o premisa básica) no suele ser tomada en cuenta. Esto significa que se resuelve enfrentándose a un problema de razonamiento.

Procuro explicar. Un diagrama de flujo me sirve como ejemplo: para obtener una sentencia, primero se debe comenzar con una demanda, luego con la contestación; le han de seguir las pruebas, y así. Se rompe el flujo o algoritmo si omito el paso de la demanda. Así, si dentro de un estado federal contamos con 32 entidades federativas, cada una con sus órganos de gobierno, lo que debemos hacer para afirmar que el juez de Uruapan, de Chiapas o de Cozumel, es el competente, consiste primeramente en precisar cuál de todas las entidades es la competente. No cabe omitir el paso de la elección de la entidad y afirmar, sin más, que cierto juez es el competente.

El razonamiento se rompe cuando se incumple el orden secuencial. En otras palabras, se incumple con alguno de los pasos u operaciones a seguirse; esto es, los pasos ordenados y necesarios para llegar a la decisión para elegir a cierto juez de un lugar específico.

Es necesario tener en claro cada uno de los pasos que han de darse y seguir la secuencia requerida. El paso para elegir una entidad y el 
paso para elegir a un funcionario estatal no son pasos paralelos, sino simultáneos; primero debe elegirse al estado, luego al funcionario de ese estado. Este encadenamiento es objeto de conocimiento del derecho interestatal.

\section{Decisiones con enfoque constitucionalista}

Otras resoluciones han reflejado una cierta directriz disciplinaria apoyada en el derecho constitucional.

Sin dejar al lado el enfoque internacionalista, la SCJN y tribunales colegiados han sostenido otra perspectiva metodológica (alternativa), partiendo del sistema federal constitucional. $\mathrm{Al}$ respecto, han dicho:

a) El artículo 121 de la Constitución Política de los Estados Unidos Mexicanos es el cimiento establecido por el federalismo para que pueda aplicarse de manera ordenada y armónica el derecho de un Estado de la Federación en otro y constituye también el ligamento de los diversos ordenamientos jurídicos estatales (SfF 1983, AR 1559/83, registro: 232016).

b) Estas cláusulas constitucionales fueron diseñadas para preservar la soberanía de los Estados en el sistema federal, previniendo la injerencia extraterritorial de las legislaciones abusivas de un Estado en el territorio de otro (SFF 2012, AD 822/2011, registro: 2001160).

c) El artículo 121, fracción I, de la Constitución Política de los Estados Unidos Mexicanos contempla como factor de equilibrio de las entidades que componen el federalismo mexicano, que en cada Estado se dé entera fe y crédito a los actos públicos, registros y procedimientos judiciales de todos los otros, reservando al Congreso de la Unión la facultad de expedir las leyes generales que habrán de regir para establecer el ámbito de validez espacial de las leyes locales a efecto de determinar un sistema que propicie la seguridad jurídica debido a la diversidad de normas que en uso de sus facultades pueden emitir (SfF 2008, AD 28/2008, registro: 169246).

Esto es, en cierta forma, los tribunales han admitido la diferencia entre las entidades, pero en su perspectiva ven la coordinación y armonización para equilibrar el poder entre ellas ("previniendo la injerencia extraterritorial de las legislaciones abusivas de un Estado en el territorio de otro"). Obsérvese que dice que es un "cimiento" del estado federal, que procura un "ligamen" entre la diversidad de ordenamientos jurídicos. 
Hay razón en las expresiones del tribunal, aunque demasiado estrechas. El enfoque epistémico no es claro.

\section{Perspectiva doctrinaria}

Son pocos los doctrinarios que han partido de una perspectiva metodológica específica para reformular los artículos 106 y 121 constitucionales. Citaré a los principales, aunque no necesariamente estoy de acuerdo con ellos.

a) Comienzo con los constitucionalistas, entre los que destacan Eduardo Ruiz y Felipe Tena Ramírez, que presentan reformulaciones derivadas del artículo 121 constitucional. El primero subsume el estudio de este texto en el DIPr (Ruiz 1902); el segundo, afirma que se trata de una disposición que afina y complementa el sistema federal, pero que el alcance de su significado le corresponde ser descrito al DIPr, pues "la Constitución no ha hecho sino aplicar, con mayor o menor acierto, nociones de aquel derecho a las relaciones de los estados entre sí" (Tena 1967, 160).

b) José Luis Siqueiros reconoce que hay una escasa literatura sobre el artículo 121 constitucional (Siqueiros 1957). Le parece que el conocimiento de esta prescripción involucra "una materia de carácter exclusivamente especulativo o teórico", y que ésta es la razón por la que el tema ha sido evadido, "aun cuando jueces y profesores hubiesen tenido la oportunidad de ahondar en sus problemas" (Siqueiros 1957, 13 y 14).

La base quinta se refiere a las profesiones. A partir de esta base, el titular de un título profesional expedido en una entidad federativa trata de que se le reconozca en otra. En esta hipótesis, la mayoría de los estudiosos del derecho interestatal suelen rechazar su interpretación con el pretexto de que se trata de un supuesto o cuestión de derecho público y no privado.

$\mathrm{Al}$ profesor Siqueiros le asombra que esta base se encuentre en el artículo 121 constitucional, puesto que "su colocación es desafortunada", pues - afirma - como se trata de una cuestión relacionada con los títulos, debió quedar en la ley reglamentaria de los artículos 4o. y 5o. constitucionales. Nótese que para este autor esta prescripción no es parte del derecho interestatal, sino del derecho de las profesiones (Siqueiros 1965, 60).

c) A Eduardo Trigueros le pareció que el artículo 121 fue un pacto de coordinación (Trigueros 1984), idea que fue secundada por su hija, Laura Trigueros, así como por Jaime Cárdenas Gracia (Cárdenas 1997). 
Laura Trigueros $(1996,240)$ lo estimó como una norma de coordinación del sistema federal, afirma que

...indispensable para garantizar su adecuado funcionamiento y también una disposición que pretende hacer prevalecer la seguridad jurídica en el Estado. Por una parte es una disposición característica del Derecho constitucional, pues contiene normas relativas a la organización del Estado y a las facultades de los órganos de poder que los gobiernan, federales y locales. Por otra, es una norma de coordinación de sistemas jurídicos, típica del Derecho internacional privado, dado que establece reglas para lograr que se respeten, mutuamente, las normas y actos jurídicos creados en los distintos Estados de la federación, se les otorgue validez y se les permita producir efectos.

\section{Walter Frisch Philipp (1989, 46) agregó que}

El constituyente mexicano dispuso en el artículo 121 de su ordenamiento el fundamento para la armonización del Derecho interlocal mexicano estableciendo en las fracciones I a IV del mismo artículo las bases que se observarán por los Estados-miembros en la creación de sus disposiciones conflictuales interlocales cuya reglamentación descansa en la competencia local (artículo 124 constitucional) sometida.

Para los Trigueros, es una regulación de coordinación federal, en tanto que para Frisch, de armonización interestatal.

d) Elisur Artega (1989, 11), al referirse al artículo 121 constitucional, expresa que "antes que principios conflictuales, es una norma de carácter constitucional que pretende circunscribir el orden jurídico de las entidades federativas a sus límites territoriales e impedir intentos indebidos de parte de ellas o excederse en su jurisdicción".

A mi parecer, todos coinciden en que se trata de armonizar y coordinar el poder con el que cuenta cada entidad federativa.

\section{GONCLUSIÓN}

Concluiré tomando en cuenta las decisiones judiciales y doctrinales a que me he referido. En general, los tribunales han admitido que el trato a los problemas de tráfico jurídico entre las entidades federativas se resuelve a partir de los discursos construidos para el derecho del trabajo, el DIPr, el 
derecho procesal, etcétera. En el fondo, han presupuesto que la explicación de la regulación interestatal (sus marcos teóricos y conceptuales) encaja en la matriz disciplinaria del DIPr, el derecho procesal o el derecho constitucional. En realidad, los tribunales ni siquiera han configurado o construido una doctrina o constructo específico para la normatividad interestatal. Los modelos mentales de los reformuladores (los personales) han sido incorporados a las decisiones producidas y, al paso del tiempo y de cambio de jueces, los resultados han sido diferentes. El efecto de esta actitud ha sido contraepistémico, pues sus decisiones han impedido una justificación jurídica.

Las decisiones producidas han conducido a someter a una misma matriz disciplinaria la problemática interestatal; esto es, las mismas teorías y conceptos elaborados para alguna de las disciplinas mencionadas, pero no la interestatal y, con ello, a un enfoque epistémico erróneo. En forma encubierta, se ha utilizado la expresión "principios", que cabe reconocer, no han sido inferidos de la normatividad interestatal.

Las resoluciones se han producido sin controvertir ni analizar la supuesta dependencia o vinculación de los enunciados interestatales al DIPr, al derecho procesal, al constitucional o al del trabajo, en la que se han apoyado. En ninguna resolución judicial se ha aludido a la posibilidad de propiedades especiales para significar los enunciados interestatales, diferentes de las propuestas por las doctrinas del DIPr, del derecho procesal o del derecho constitucional ni se ha proporcionado alguna secuencia de razones que conduzcan a persuadir y, menos, a convencer que la problemática interestatal cabe como un apartado de las citadas disciplinas, ni, mucho menos, se ha esbozado la posibilidad de contar o construir un discurso especial para la regulación interestatal. La parte justificativa de las decisiones ha estado ausente. Somos herederos de un conocimiento acumulado, pero atrofiado.

Inferencias analíticas, a partir de alguna prescripción interestatal, no se han producido; de igual forma, un enfoque epistémico específico ha estado ausente. La ausencia de una autonomía disciplinar ha impedido la construcción y avance del derecho interestatal. ${ }^{22}$

22 Para la autonomía disciplinar se han llegado a afirmar diversos argumentos: a) que cada disciplina opera con lógicas distintas, b) se trata de estudios científicos separados, c) el campo de conocimiento particular da lugar a una disciplina autónoma, d) debe tomarse en cuenta la especificidad del objeto de conocimiento y la perspectiva empleada para estudiarlo, y e) cada disciplina tiene su propio campo de análisis (Lariguet 2008). 
Esta actitud de los tribunales ha reflejado una falta de sensibilidad en la impartición de justicia y carencias en el conocimiento de conceptos y realidades. Representa una apatía máxima. Parece resultarles más accesible decidir por la intuición o el sentido común, que incursionar en la búsqueda de decisiones más racionales, lo que ha parecido complicado. En cualquier caso, la ley del menor esfuerzo parece haber sido su prédica.

$\mathrm{Al}$ presuponer una perspectiva internacionalista, se ha recurrido a una subsunción, que no cabe aceptar, por dos razones: 1) no se trata de resolver problemas de personas de diversas nacionalidades o soberanías, y 2) en la normatividad internacional no existe una Constitución mundial que se imponga sobre cada Estado de la comunidad internacional.

Si examinamos la perspectiva histórica, advertiremos que no se ha entendido que el artículo 121 fue tomado de la Constitución de Estados Unidos, donde esa disposición se estableció precisamente para evitar darle tratamientos internacionales a los problemas interestatales. ${ }^{23}$ Pero en México, algunas resoluciones y parte de la doctrina han hecho lo contrario.

Los argumentos judiciales producidos no sólo han sido carentes de racionalidad y perspectiva histórica, sino pobres, prejuiciados y con gran confusión de conceptos jurídicos, carentes de una base epistémica. Ningún tribunal ha tomado en cuenta la función específica de los enunciados prescritos, a partir de los cuales debería conformarse una explicación de las relaciones interestatales, no las internacionales.

En algunas decisiones se ha apelado a razones tomadas del derecho del trabajo, del DIPr, del derecho procesal; se han mezclado enfoques político-ideológicos de "soberanía", y en ocasiones se ha hecho presente la

23 Para Robert A. Sedler (1981), la cláusula de entera fe y crédito estadounidense no se originó en la necesidad de solucionar conflictos de leyes; es decir, partir de normas de conflicto. Más bien, fue para establecer un medio de control constitucional sobre los estados. Afirma que al momento de la Constitución ni siquiera se conocían los problemas de "elección del derecho aplicable". La cláusula constitucional surgió para promover la igualdad entre los estados y el respeto a la soberanía de cada estado dentro de un gobierno federal. Así, la SCJN interpretó la cláusula para evitar la discriminación contra las leyes de otro estado, y que en cada estado se ejecutaran las sentencias sin discriminación. Para Sedler (1981, 347), la Corte Suprema no le impuso más límites al poder de los jueces de cada estado para que decidieran en una u otra forma sobre el "derecho aplicable". La tesis corresponde a la obra de Sedler (1981). Sus afirmaciones se encuentran respaldadas por Nadelmann $(1972,169)$ en un acucioso estudio del origen de la cláusula (Silva 2008, artículo 121). 
ignorancia, la gran ocurrencia o la intuición. No se han incluido precisiones conceptuales del discurso utilizado ni clasificación del estado de cosas ni el uso de reglas del lenguaje. La generalización y abstracción ha estado ausente. A mi parecer, la necesidad de resolver y la falta de marcos teóricos o su desconocimiento han tomado por sorpresa a los jueces durante cerca de doscientos años. Se ha estado resolviendo, pero se ha carecido de una sólida base epistémica.

A pesar de las grandes diferencias metodológicas presupuestas (incluso contradictorias y excluyentes), en ocasiones en forma simultánea en el tiempo, en ningún momento los tribunales han atendido las diferencias en estos enfoques ni se han ocupado por elegir uno y desechar otros. Se ha carecido de un argumento sistemático, pues no se ha tomado el contenido de las prescripciones interestatales, ni siquiera su función ni su contexto constitucional.

Si se contara o si tuviera un punto de partida definido se facilitaría la construcción de decisiones, pues se tendría una base para reformular. Con ello, se cumpliría un objetivo de gran importancia. El objetivo sería hacer racionalmente comprensible los materiales interestatales para darle una explicación plausible. Tal y como se han producido, las decisiones judiciales aportadas no han facilitado la toma de una decisión, ni criterios para la producción del derecho. Tampoco han permitido ordenar o sistematizar el derecho interestatal.

Una conclusión a la que puedo arribar hasta aquí, es que se ha creído (enfatizo en el verbo creer) que un derecho interestatal (lenguaje objeto y metalenguaje) son parte del DIPr, del derecho procesal o del derecho constitucional. Pero una cosa es creer y otra conocer. No vale solo creer para continuar construyendo normas y metalenguaje, sino que es necesario saber y conocer. Se ha carecido de un enfoque epistémico.

No hay que olvidar que en los artículos 106 y 121 se presupone un estado federal, que regula las relaciones horizontales entre los estados miembros, procurando que no se interfieran entre ellos, y, que, en su caso, se armonicen. Lo anterior, con el fin de coordinar sus relaciones de poder; que ninguna entidad se sobreponga a otra, ni que se encuentren aisladas entre sí; que se acoplen en sus relaciones jurídicas y de poder entre ellas, enlazando la solución de los problemas de tráfico jurídico interestatal, evitando los desacoples o perturbaciones a las situaciones de tráfico jurídico interestatal. 
Como es sabido, la interpretación de cualquier texto constitucional nos permite precisar el punto de partida de cualquier ley secundaria. Fija el inicio de la cadena de validez normativa. Si acaso se asume un enfoque teleológico, la precisión de la finalidad facilita la interpretación de cualquier texto derivado.

Una correcta interpretación uniforma a todas las entidades en torno al reconocimiento de ciertos actos de cada una, sin necesidad de que todas las leyes sustantivas se uniformen. Simplemente no es necesario que tengan que uniformarse ni que tengan que optarse por "códigos nacionales" o únicos,$^{24}$ por el hecho de que cada entidad haya estado legislando con autonomía y que sus leyes sean diferentes de las de otras. El Estado federal debe admitir las diferencias entre las distintas comunidades sociales del país sin tener que optar por una "centralización" ni una uniformidad.

El texto constitucional admite la diferencia entre los ordenamientos, pero necesariamente no los armoniza. Lo prescrito en su preámbulo del artículo 121 y en las bases que contiene (como les llama el texto constitucional) deben ser tomadas en cuenta por todas las autoridades, pues de esta manera prevalece la concordia entre las diferencias y se respeta el orden jurídico de cada una.

El artículo 121 se encuentra en el título quinto de la Constitución, denominado "De los estados de la federación y de la Ciudad de México". A pesar de que se trata de un argumento sedes materiae, es obvio que ahí fue colocado a propósito por el constituyente. ${ }^{25}$ No presupone relaciones entre Estados de la comunidad internacional ni prescribe actos en los que deba introducirse el gobierno federal en la actividad intraestatal.

\section{REFERENCIAS BILIOGRÁFICAS}

Alahourrón, Carlos E. y Bulygin, Eugenio. 2002. Introducción a la metodología de las ciencias jurídicas y sociales, Buenos Aire, Astrea. Anales del Foro Mexicano 7(I). 1864. Archivo General de la Nación.

24 En este momento se encuentra en vigor una reforma constitucional, que debe dar lugar a un código nacional de procedimientos civiles aún no conocido.

25 La atribución de significado a un enunciado dudoso se realiza "a partir del lugar que ocupa en el contexto normativo". Se piensa que "la localización topográfica de una disposición proporciona información sobre su contenido" (Ezquiaga 2001, 160). 
Anales del Foro Mexicano 6(II). 1865. Archivo General de la Nación.

ARTEAGa Nava, Elisur. 1989. "Análisis de la fracción II del artículo 121", en Octavo Seminario Nacional de Derecho Internacional Privado, México, UNAM.

Bulygin, Eugenio. 1991. "Dogmática jurídica y sistematización del derecho", en Alchourrón, Carlos (comp.), Análisis lógico y derecho, Madrid, Centro de Estudios Constitucionales.

CíCeres Nieto, Enrique. 2015. "Capítulo 60. Epistemología jurídica aplicada", en FABRA, Jorge Luis (coord.), Enciclopedia de filosofía y teoría jurídica, vol. III, México, UNAM, Instituto de Investigaciones Jurídicas.

Cárdenas Gracia, Jaime. 1997. "Artículo 121”, en Constitución Política de los Estados Unidos Mexicanos comentada, México, Poder Judicial de la Federación-Consejo de la Judicatura Federal-UNAM.

El Foro, México, 19 de agosto de 1873.

EZQUIAGA, Francisco Javier. 2001. "Argumentos interpretativos y postulado del legislador racional", en Interpretación jurídica y decisión judicial, México, Fontamara.

Dworkin, Roger B. 1996. Limits: The Role of the Law in Bioethical Decision Making, Indiana, University Press.

FRISCH PHILIPP, Walter. 1989. "Las entidades federativas y la federación en el derecho conflictual mexicano", en Octavo Seminario Nacional de Derecho Internacional Privado, México, UNAM.

IgLESIAS, José María. 1874. Estudio constitucional sobre las facultades de la Suprema Corte de Fusticia, México, Imprenta de Díaz y White.

KUHN, Thomas S. 1971. La estructura de las revoluciones científicas, México, FGE.

LARiguet, Guillermo. 2008. Problemas del conocimiento jurídico, Buenos Aires, Ediar.

G. W. Bartholomew. 1958. "Legal Implications of Artificial Insemination", The Modern Law Review, 3(21).

KART, Hans. 1972. Conflict of Laws: International and Interstates, Selected Essays, Boston, The Hague, Netherlands, Martinus.

MONTIEl y DuARTe, Antonio. 1874. Estudio constitucional sobre la soberanía de los estados de la República mexicana, México, Imprenta de Díaz de León y White.

Niboyet, Juan Paulino. 1974. Principios de derecho internacional privado, trad. de Ramón Rodríguez, México, Editorial Nacional.

Esta obra está bajo una Licencia Creative Commons

Atribución-NoComercial-SinDerivar 4.0 Internacional, IIJ-UNAM.

Boletín Mexicano de Derecho Comparado, núm. 156, pp. 1637-1667. 
Niboyet, Juan Paulino. 1996. Principios de derecho internacional privado, Madrid, Reus.

RuIZ, Eduardo. 1902. Derecho constitucional (edición facsimilar), México, Tipografía Aguilar.

SEDLER, Robert A. 1981. "The Perspective of Constitutional Generalism", en Constitutional Limitations on Choice of Law, Hofstra Law Review. 1(10).

Shreve R., Gene y Buxbaum, Hannah. 1997. A Conflict of Laws, Anthology, Carolina, Carolina Academic Press.

SILVA, Jorge Alberto. 2014. Derecho interestatal mexicano. Estudio autónomo de la regulación de los problemas de tráfico jurídico entre las entidades federativas, México, UACJ.

SiLVA, Jorge Alberto. 2008. "La regulación constitucional del derecho interestatal. Algunas notas sobre el primer párrafo del artículo 121", en Obra homenaje a Rodolfo Cruz Miramontes, t. I, México, UNAM, Instituto de Investigaciones Jurídicas.

SiqueIros, José Luis. 1957. Los conflictos de leyes en el sistema constitucional mexicano, Chihuahua, Universidad Autónoma de Chihuahua-Escuela de Derecho.

SIQUeIROS, José Luis.1965. Panorama del derecho mexicano. Sintesis del derecho internacional privado, México, UNAM.

Suprema CORTE De JustiaiA DE LA NACión. 2005. Jurisprudencia histórica y otros documentos de la época (1870-1910), versión en disco óptico, México, Suprema Corte de Justicia de la Nación.

TAMAYO Y SALMORÁn, Rolando. 2003. Razonamiento y argumentación jurídi$c a$, México, UNAM.

Tena Ramírez, Felipe. 1967. Derecho constitucional mexicano, México, Porrúa.

Trigueros SARAVIA, Eduardo. 1984. "El artículo 121 constitucional", Revista de Investigaciones furídicas, 8(1).

Trigueros, Laura. 1996. "La interpretación del artículo 121 de la Constitución; la doctrina constitucional", en Barra Mexicana de Abogados, Homenaje a Fernando Alejandro Vázquez Pando, México, Themis.

VÁzQuez, Rodolfo. 2008. Teoría del derecho, México, Oxford University Press.

Villela, José Ma. 1878. "Conflicto de leyes" (colaboración editorial), en El Foro, 28(IV). 